Article

\title{
Investigating Preconditions for Sustainable Renewable Energy Product-Service Systems in Retail Electricity Markets
}

\author{
Widha Kusumaningdyah ${ }^{1,2}\left(\mathbb{D}\right.$, Tetsuo Tezuka ${ }^{2}$ and Benjamin C. McLellan ${ }^{2, *(\mathbb{D})}$ \\ 1 Department of Industrial Engineering, Faculty of Engineering, University of Brawijaya, \\ Malang 65145, Indonesia; widhadyah@ub.ac.id \\ 2 Graduate School of Energy Science, Kyoto University, Kyoto 606-8501, Japan; tezuka@energy.kyoto-u.ac.jp \\ * Correspondence: b-mclellan@energy.kyoto-u.ac.jp
}

Citation: Kusumaningdyah, W.; Tezuka, T.; McLellan, B.C.

Investigating Preconditions for Sustainable Renewable Energy Product-Service Systems in Retail Electricity Markets. Energies 2021, 14, 1877. https://doi.org/10.3390/ en14071877

Academic Editor: Adam Smoliński

Received: 30 December 2020

Accepted: 3 March 2021

Published: 29 March 2021

Publisher's Note: MDPI stays neutral with regard to jurisdictional claims in published maps and institutional affiliations.

Copyright: (C) 2021 by the authors. Licensee MDPI, Basel, Switzerland. This article is an open access article distributed under the terms and conditions of the Creative Commons Attribution (CC BY) license (https:/ / creativecommons.org/licenses/by/ $4.0 /)$.

\begin{abstract}
Energy transitions are complex and involve interrelated changes in the socio-technical dimensions of society. One major barrier to renewable energy transitions is lock-in from the incumbent socio-technical regime. This study evaluates Energy Product-Service Systems (EPSS) as a renewable energy market mechanism. EPSS offer electricity service performance instead of energy products and appliances for household consumers. Through consumers buying the service, the provider company is enabled to choose, manage and control electrical appliances for best-matched service delivery. Given the heterogenous market players and future uncertainties, this study aims to identify the necessary conditions to achieve a sustainable renewable energy market. Simulation-Based Design for EPSS framework is implemented to assess various hypothetical market conditions' impact on market efficiency in the short term and long term. The results reveal the specific market characteristics that have a higher chance of causing unexpected results. Ultimately, this paper demonstrates the advantage of implementing Simulation-Based Design for EPSS to design retail electricity markets for renewable energy under competing market mechanisms with heterogenous economic agents.
\end{abstract}

Keywords: Energy Product-Service Systems; renewable energy; energy transition; retail market

\section{Introduction}

It has been acknowledged that energy transitions are challenged with lock-in from the incumbent socio-technical regime. Transitioning energy systems require social commitment, involving producers, users, financial support and political will from various actors. Without commitment, investment and innovation to enable it, the transition cannot be realized. Policies have been introduced to stimulate renewable energy technology installation and escape system lock-in-for example, feed-in-tariffs and other subsidies or support systems [1]. Nonetheless, the effectiveness of such policies varies among regions, depending on actors' behavior and decision-making processes. Therefore, policymakers are expected to consider the human dimensions of energy systems alongside the technological and organizational dimensions.

On the other hand, while some countries show progress in transitions and have begun to successfully cut emissions, it may harm the economic sustainability of future energy markets if profit from electricity sales, particularly for grid-balancing controllable generation (mostly fuel-based) in transitional markets, is reduced by renewable uptake. The more renewable electricity generated, the lower the operational cost of the generation facility; thus, price levels are set in accordance to the levels of wind and sun as such renewable generation expands. Such renewables also tend to produce maximum power at the same time, meaning that in high-renewable markets, they must sell at the same time, making their own profitability lower (unless they are integrated with storage to enable redistribution of energy to higher-cost times). For this reason, zero-marginal-cost energy (renewable) markets integrated with marginal-cost-based markets may destroy electricity prices and limit revenue [2]. Ultimately, there is a strong need for new energy market 
designs for renewable energy. The market should be designed to achieve an efficient balance of supply with demand and to instigate more investment through alternative revenue generation.

Energy Product-Service Systems (EPSS) with renewable energy (Re-EPSS) are evaluated as an alternative sustainable renewable market mechanism in this study. EPSS aim to improve resource efficiency, while maintaining benefits for society by providing electricity service performance using energy, products and operation of dwellings for a household [3]. Service provision releases consumers from the requirement to purchase electrical appliances to satisfy their needs. Consumers shifting from buying products to buying services allows the service-providing company to extend their control of products and use them strategically to achieve both the desired performance and business objectives.

EPSS is theoretically matched with the requirement for sustainable future renewable markets for its ability to reduce and control demand, as well as providing a revenue stream that does not fully depend on electricity prices. An EPSS-providing service allows the company to control and manage appliance usage and operation and demonstrates greater flexibility from the demand side to respond to supply uncertainties. To achieve service excellence, the EPSS provider also invests in storage as reserve capacity for when demand for service is required. Moreover, EPSS creates its revenue from service value generated from appliances and electricity performance. Even in the case of zero-price electricity, the EPSS business model is projected to generate more revenue rather than merely trading electricity sources.

Nonetheless, evidence shows that human cognitive bias and bounded rationality are major challenges [4], which leads to individuals making purchasing decisions that are not ideal (for example, purchasing lower capital cost equipment that is less efficient and therefore higher-cost in the long term). Such behavior hinders the energy transition and the efficiency of the retail market. While it is possible to address the present bias in society, identifying the bias is difficult [4]. Therefore, instead of attempting to develop a specific market design, this study aims to identify the required preconditions for EPSS to achieve a sustainable renewable energy market design. In this case, a sustainable renewable energy market is a market including high levels of zero-marginal-cost renewables.

To achieve the objective, this study implements the Simulation-Based Design for EPSS framework (SBD for EPSS). The method incorporates an agent-based model, to simulate the interaction of heterogenous actors in the energy system using a worst-case method to identify the unfavorable inputs that harm the design performance.

Outputs from the modeling allow us to suggest specific market characteristics that lead to unexpected performance. Recommendations can then be provided to satisfy required preconditions for competing markets between conventional Energy and Product-Oriented Systems (EPOS) and EPSS to achieve renewable energy market efficiency in the short term and the long term. This paper also adds to the literature on energy transitions, as the first to provide a method to design retail electricity under competing market mechanisms for renewable energy considering heterogenous economic agents.

The paper is structured as follows: Section 2 gives an introduction to the related literature as extended background; Section 3 describes the methodology developed in this study in order to design and evaluate EPSS; Section 4 describes the results and discusses them with analysis; Section 5 then presents the conclusions.

\section{Related Literature}

\subsection{Escaping Carbon Lock-In}

Energy transitions are complex phenomena that involve multiple dimensional aspects ranging from technological and economic feasibility and resource availability to political willingness and social acceptability [5-7].

A variety of policies have been introduced to stimulate renewable energy technology installation. Most countries rely on feed-in-tariffs (FiT) as a measure to promote renewable energy development (e.g., [1,8-11]). These offer a profit guarantee for long-term contracts 
(typically ranging from 15 to 20 years) to renewable energy developers. Until now, FIT policies have been considered the most successful measure to promote renewable energy around the world, notably in Germany [12]. FiTs are considered more effective to influence photovoltaic (PV) installation compared to other measures, such as renewable energy certificates [1]. Nonetheless, it was also found that in certain cases-for example, in Australia-that FiTs correspond to a great number of electricity disconnections from the grid, which is possibly due to a high burden of capital cost payoffs [11]. FiTs also often put a burden on government funds [13]. Despite their drawbacks, many countries depend on FiTs in promoting energy transitions [14]. Despite countries struggling with carbon lock-in, some have shown impressive progress in terms of energy transition. The combination of timing and impact of socio-political alignment of endogenous and exogenous events creates a catalyst and support for the transition. In Germany, political stability, the coordinated policymaking style and grassroots support, combined with suitable policies, have enabled the vast deployment of wind power and photovoltaics to replace power from coal $[15,16]$. Simultaneous external pressures and the recognition of performance problems in the incumbent systems can weaken system lock-in and create urgency towards the energy transition [17].

Another alternative is the Net-Metering (NEM) policy, which allows a consumer who generates their own electricity to fulfill their energy needs directly on-site and to receive financial credit on their electricity bills for any excess electricity fed to the main grid [18]. The policy offers an alternative option for positive investment opportunities especially from small scale PV generation, such as in the residential sector, which eventually supports the development of distributed renewable energy generation $[19,20]$.

The above description shows the importance of human dimensions of energy systems to overcome lock-in in socio-technical systems. Therefore, while it is important to focus on the physical aspects of the systems (e.g., infrastructure, technology and organization), policymakers are expected to develop measures that also consider the human dimensions of energy systems [21-24].

\subsection{Future Renewable Energy Market}

Renewable energy, especially wind power and photovoltaics, is expected to form the basis of a future, low-carbon energy system. Wind power and PV facilities have been characterized by high investment cost and marginal costs that are close to zero. While the capital costs have been declining rapidly [25], the marginal costs remain low. These characteristics of renewable energy bring issues for future sustainable energy markets. At present, feed-in-tariffs provide long-term guarantees to compensate the profit risk from electricity price uncertainty. Nonetheless, when renewable energy uptake dominates the total energy mix, wind and PV will reduce electricity market prices and the operating time of fossil-based power stations. Integrating renewable energy markets into current electricity markets will destroy power prices in the marginal-cost-based wholesale spot market [2]. Despite the objective of market deregulation to maintain electricity prices, to achieve almost zero electricity price through renewable energy transitions creates problems for future energy market sustainability, since the market cannot rely on wind and PV to refinance renewable energy development [2]. The more wind and PV facilities are built and produce electricity concurrently, the lower the electricity market price. Once investment cost is recovered, the existing facilities can produce electricity at effectively zero marginal cost, discouraging new entrants to the market. It was suggested that future energy markets should be designed to achieve an efficient balance of supply and demand by steering the installation capacity and by sending signals for more investment in renewable energy production and supporting facilities [2].

To achieve sustainable renewable energy markets, several options are proposed, including "power-only" markets and markets with Capacity Remuneration Mechanisms (CRMs) [2,26]. Others suggest business models that appear to be suitable for renewable energy: service mobility, load management and storage are repeatedly mentioned for 
renewable energy business models (e.g., [27]). However, the exact configuration of the new market and business model requires further study.

\subsection{Promoting Energy Product-Service Systems for Sustainable Energy Market Design}

This study suggests Energy Product-Service Systems (EPSS) for sustainable renewable energy markets. EPSS were first introduced by the authors of the present study [3], aiming for their application in a liberalized energy market. EPSS are defined as a "system" that delivers electricity service performance using energy, products and operations of dwellings by incorporating the basic functional systems for a household [3]. The underlying motivation of EPSS introduction is the realization that energy is a form of "derived demand", where end-users' needs represent a certain performance level of energy-provided service, rather than energy itself. For example, in winter, households have a real demand for heating (service) at a set temperature (performance level) rather than the input electricity and heating machines. For this reason, energy and certain appliances should be delivered as energy service performance for end-consumers. Service delivery through EPSS is anticipated to improve resource efficiency, while maintaining benefits for society. This can arguably be achieved by the simplest form of EPSS, where household consumers are released from appliance ownership and provided with energy service performance instead.

The benefit of releasing consumers from appliance ownership can minimize the costs and risks associated with ownership [28]. Additionally, consumers may be able to obtain more value from customization or higher quality of performance [28,29]. For businesses, service-oriented provision arguably creates opportunities to offer more value for consumers, thus increasing their competitiveness [30-32]. It is also anticipated that EPSS will result in better consumer feedback [32] and thus improve satisfaction. Furthermore, consumers shifting from buying products to buying services allows the company to extend their control of products [33] and use them strategically to achieve both the desired performance and business objectives. For society, the potential advantage of EPSS could be bolstered by improving the environmental performance, notably the reduction of resource consumption, waste and emissions.

Concerning electricity market liberalization, it is expected to provide opportunities to create value-added services for retail consumers, to ensure that the benefit from the market is distributed to consumers through prices and service quality attributes that match with consumers' values and preferences [34]. A well-functioning liberalized market also expects retailers' ability to offer various service options to be coupled with consumers' ability to compare and make informed choices [35]. Nonetheless, as a highly commoditized product, electricity provisions are difficult to differentiate. Current retail markets distinguish their offers through pricing plans or billing. It may also include ancillary services, though society appears to not be ready to adopt this generally.

Benefit has been recognized from market liberalization, but mostly for the supplier side $[34,36]$. On the other hand, lower electricity prices, as an expected benefit for household consumers, have not always been achieved. In fact, there have been occasions when liberalized electricity prices have been higher than monopolistic markets [37,38]. Market imperfections, such as complexity of information provision and switching cost, have been identified as the cause of retail electricity market failures [39-41]. Electricity retail consumers are poor electricity shoppers because their cognitive processes are limited in terms of computational capability, time and willpower [42-46]. These cognitive biases influence their valuation of retailers' provisions in power-only markets with distinguished pricing plans.

Others have argued that one of the critical preconditions for retail consumers to obtain benefits from a liberalized electricity market is for them to be able to see and to respond to real-time price changes [34]. Once consumers (demand side) can actively participate and react to variations in market prices, full integration of demand-side responses to energy prices and reliability criteria can be achieved, leading to market efficiency [34]. For this reason, there is hope that the expanded development and use of smart devices and smart 
home technologies will materialize the required preconditions [47]. Unfortunately, consumers are also poor shoppers for highly efficient technology. Myopic consumers who are incapable of assessing the long-term risks or benefits of their choices [44], have been widely identified in investigations on highly efficient appliances and technology as well $[4,44,48]$. Therefore, expecting consumers to choose the latest technology, which is more expensive despite being potentially more efficient, may lead to other buying "mistakes".

EPSS releasing consumers from ownership allows the company to control, choose appliances and electricity sources. It is suitable for renewable energy futures and liberalized retail markets where demand-side participation is indispensable for supply-demand balance to achieve market efficiency. It appears that EPSS' characteristics align with the requirements of liberalized electricity retail markets and renewable energy markets.

\section{Methodology: Simulation-Based Design for EPSS Framework}

For the purpose of this study, the Simulation-Based Design for EPSS framework (SBD for EPSS) is used to design an EPSS for renewable market mechanisms in retail electricity markets. SBD for EPSS is a simulation framework that incorporates agentbased modeling and worst-case methods to design an EPSS, which represents a new system with multiple interacting actors under limited available knowledge. EPSS provides an alternative mechanism to address problems in current energy markets and energy transitions. However, a hasty transition to a new mechanism such as EPSS may cause less efficient results than the incumbent system and harm the stakeholders' benefit.

To date, the lack of available knowledge about EPSS is a challenge when designing a mechanism that will lead to well-performing systems. Future uncertainties and conditions expose every plausible market design and investment decision to risks. The worst-case method is incorporated to identify the unfavorable conditions that lead to unexpected performance. Instead of seeking the design with the best performance, it is better for Re-EPSS with a considerable amount of uncertainty to err on the safe side through the identification of worst-case scenarios [49].

Agent-based simulation (ABS) is often applied to simulate energy systems considering economic agents with bounded rationality. It is advantageous to replicate the dynamics of liberalized electricity markets and energy transition progress by incorporating heterogenous actors' behavior [50,51]. It also allows the exploration of the role of community players with their cognitive bias in energy transitions [52]. The exploration of plausible trajectories of energy transitions given uncertain socio-technical conditions is also possible with ABS [53,54]. These advantages are suitable for the present study, wherein multiple interacting market players with heterogenous characteristics and behaviors have anticipated impacts on EPSS performance for renewable energy market mechanisms.

Finally, simulation-based design (SBD) plays a significant role in the evaluation and comparison of Re-EPSS design market performance with incumbent market mechanisms under various conditions. Emphasizing the use of simulation as a tool to design, evaluate and analyse the designed SBD is beneficial for Re-EPSS market design systems that require comprehensive analysis to predict the outcomes before consuming resources, effort and time by eliminating risks of design failure as soon as possible [55]. This approach allows the use of hypothetical environments, as well as infrastructure for collaborative engineering and integration technologies and tools [56,57].

The model simulates the impact of market actors' behavior and decision processes on market efficiency in both the short term and long term. The simulation is written using Python 3+ language programming, using, in particular, the Mesa module, a framework for agent-based simulation [58]. The design is developed by incrementally modifying the parameters in the incumbent system and analysing the conditions that cause the worst results. 


\subsection{Model Overview}

A hypothetical market, focusing on the retail market, is developed to demonstrate the identification of required preconditions for Re-EPSS market design. The market consists of an appliance producer and electricity retailers that purchase and sell electricity to the wholesale market, which serves a community of 100 households. Consumers demand three types of services, comprising food preservation, heating/cooling services and laundry services.

For each type of service demand, appliance producers provide two groups of appliances, which are categorized based on their efficiency. Each group of appliances consists of several appliance specifications which are distinguished by price. However, in general, the price of highly efficient appliances is set to be more expensive than that of low-efficiency appliances.

Some retailers and consumers exhibit loss-averse behavior, where they avoid exposure to risky choices due to uncertain results. These types of retailers and consumers represent late adopters of new system mechanisms. On the other hand, innovative retailers initiate the deployment of Re-EPSS mechanisms to satisfy consumer demand, and alternative-seeker consumers are identified in liberalized markets as early adopters of the new system due to their awareness toward switching cost [59]. In this market, consumers are endowed with one of a number of preferences, including cost-oriented consumers, performance-oriented consumers and environmental-oriented consumers, which reflects their preference toward supply reliability. Moreover, three cognitive biases are assumed to influence consumer decision processes, comprising loss aversion bias, status quo bias and social proof [35].

Status quo bias is caused by habitual behavior and cognitive comfort, which is created by previous monopolies promoting consumer loyalty through long-term relationships [59,60]. It appears that such comfort results in feelings of satisfaction with the incumbent provider [59]. For this reason, households rarely search for alternative retailers, but when they search, households perceive more advantages to the incumbent [41]. Closely related to status-quo bias, consumers on average are either risk-averse or loss-averse. In electricity-related markets, it was found that typical consumers refuse to consider different options because either they are afraid that they will lose some benefit compared to the current option (risk-averse) or have a perception that there is insignificant economic benefit compared to the cognitive cost of changing their choice (loss-averse) [61]. Concerning social proof, it was argued that consumers do not exercise their choice because the social standard is not to switch [35]. It has also been observed that household consumers follow social influences depending on the influencer [62]. In some cases, the strength of relations between individuals is more important than the number of connections in influencing individuals' choices [63].

For the purpose of this study, the market also covers the wholesale market as a poweronly market, where fossil fuel and renewable electricity is exchanged. The wholesale market satisfies demand from EPSS and the incumbent system, which is referred to as Energy and Product-Oriented Systems (EPOS). For simplicity in capturing market response to price signals, all electricity demand from EPOS is satisfied in the spot market. Spot prices in the wholesale market are determined by the renewable energy mix in total energy consumption. Power-only market is equipped with a capacity market, to secure electricity supply when needed. Re-EPSS providers also invest in demand response and storage capacity to deliver services, depending on consumer preferences and cost constraints in service consumption. In a market with EPSS, a Virtual Power Plant (VPP) is incorporated to manage and control electricity supply-demand balances for EPSS consumers. Electricity generation and storage are used by prioritizing EPSS consumers before the VPP dispatches any excess electricity to balance the demand from the EPOS market. Figure 1 summarizes the market players in the observed market. The materials and methods should be described in sufficient detail to allow others to replicate and build on the published results. 


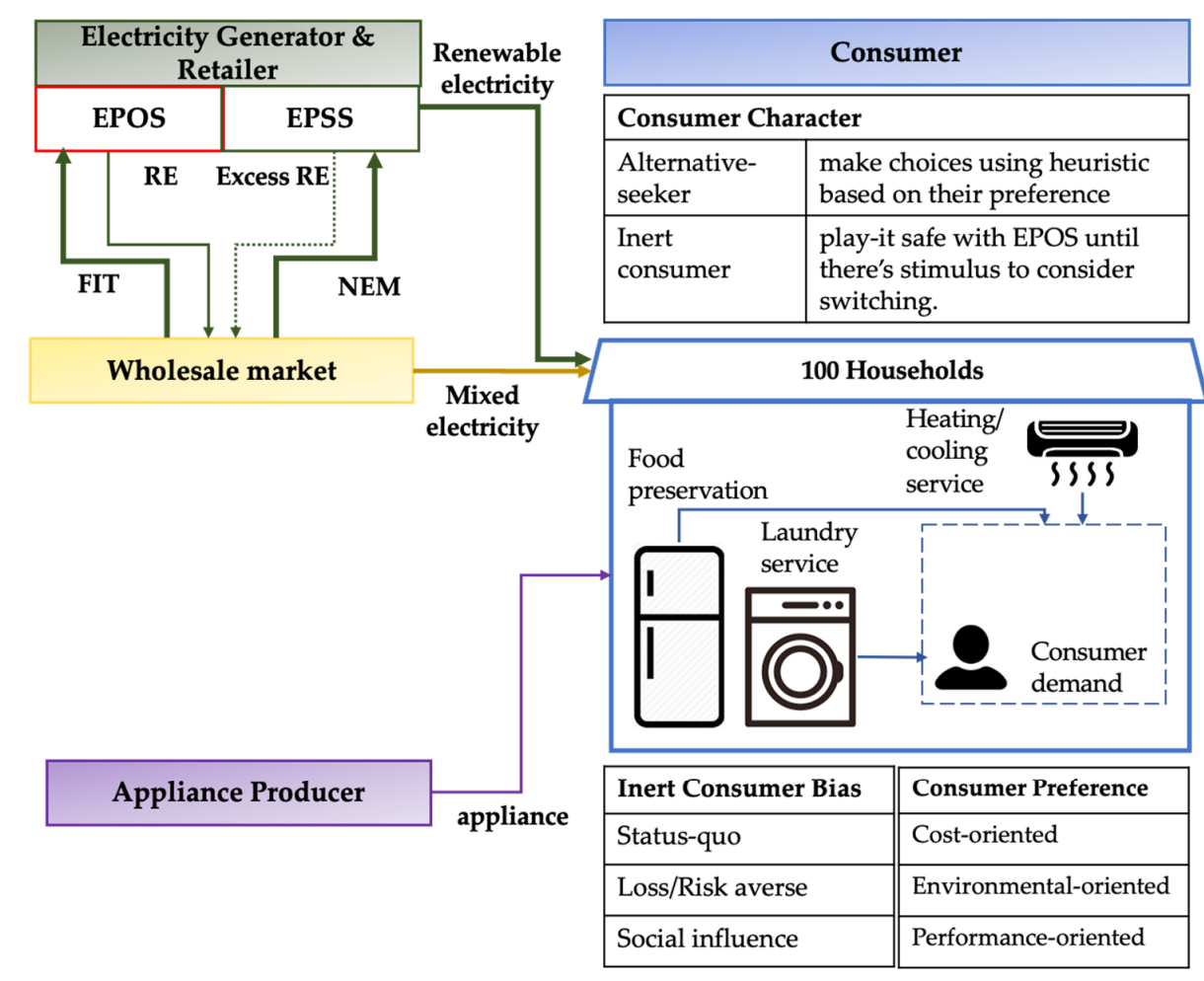

It is assumed that the regulator is targeting $80 \%$ renewable energy penetration in 50 years

Figure 1. Market players' interaction in the observed market. (NEM = Net metering; RE = Renewable Energy; FIT = Feed-in-Tariff).

\subsection{Market Players' Behavior}

Both retailers in EPOS and EPSS behavior are motivated to maximize revenue from renewable energy investment. Ultimately, the critical decision for both retailers is investment decisions on PV facilities. Investment decisions are influenced by prospective benefits in the future, which, in this study, are signaled by demand trends and revenue trends. In addition, for EPSS retailers, their investment decision involves electricity storage for reserve supply when needed.

EPOS and EPSS retailers have different sources of revenue. In EPOS, the revenue is derived from electricity sales in the wholesale market and retail market, and profit depends on both FiT and wholesale prices. The bigger PV installed capacity, the higher volume of electricity sales. Meanwhile, EPSS retailers rely on a constant service rate which is billed periodically (e.g., monthly) from the consumer. Another profit source of EPSS retailers also includes excess electricity sales in the wholesale market.

Consumer behavior is intuitively directed by their needs and preferences. In EPOS, consumers are required to choose and purchase appliances, create service demand based on environmental stimuli, pay electricity bills of an amount depending on the consumption, unconsciously evaluate satisfaction, provide feedback when asked and decide on appliance replacement. EPOS consumers are assumed to voluntarily pay the surcharge cost of renewable electricity but are not interested in purchasing ancillary services because it requires high investment with uncertain benefit. In a market where EPOS and EPSS compete, however, consumers first make the decision of whether to switch to EPSS or remain with the status quo, based on their characteristics and preferences. Only alternativeseeker consumers compare the attributes of products/services based on their interest to make a choice on a system or appliance. Inert consumers, on the other hand, postpone 
their decision until the market provides signals that address their bias in decision-making. Eventually, every period, wholesale electricity prices and FiT rates are adjusted, considering the renewable energy mix in total electricity consumption.

The comprehensive algorithm of market players' decision processes and behavior is presented in Appendix A.

\subsection{EPSS Design}

EPSS provides services as a bundle of electrical appliances and electricity supply to deliver expected performance for household consumers. In EPSS, it is possible to manage the condition of the collected appliance through regular maintenance and replacement policy. All appliances used in EPSS are provided with regular maintenance to maintain the machine's performance, which leads to a slower degradation rate than those which do not receive regular maintenance. Air conditioner efficiency degradation is calculated using the formula adopted in [64]. Hence,

$$
\text { Efficiency degrade }=\text { Efficiency nominal } \times(1-M)^{\text {Age }}
$$

where $M$ is the maintenance factor, whose value is 0.01 for expertly maintained equipment and 0.03 for unmaintained, as per [64]; and age is appliance age in years. The service ends when the appliance performance is lower than the threshold. This policy is intended to prolong the product lifespan, thus expectedly reducing the production requirement. The company takes back all obsolete appliances for further reprocessing or disposal.

The present study introduces three types of EPSS, which are differentiated by performance level to serve different consumers' preferences.

The first type of EPSS design is intended for cost-oriented consumers, whose interest is in minimizing the total cost of service consumption. These consumers limit their consumption costs and are willing to compromise on the performance level of the service. To satisfy the requirement, service providers invest in technology to obtain and deliver information about real-time electricity demand and control the usage for minimum performance when service demand occurs during peak times. The second EPSS type is designated for environmental-oriented consumers, whose aim is to minimize emissions generated from service consumption. For environmental-oriented consumers, the service provider invests in highly efficient appliances and technology to monitor real-time electricity demand and control the service performance in the event that demand occurs during peak times. For consumers who are performance-oriented, the service provider prepares EPSS type 3. This type of EPSS satisfies consumer demand for premium service demand, where consumers do not want curtailment or postponement of demand fulfilment, and cost does not limit them from purchasing the service. For these consumers, the company invests in highly efficient appliances and allows consumers to have full control over operation and use whenever it is needed. The EPSS contract between the consumer and company ends when an appliance needs to be replaced. In EPSS, the appliance is replaced when its efficiency degradation reaches more than $15 \%$ of the initial condition.

The services are categorized into two groups, which are characterized by the reliability performance, i.e., (1) negotiable vs. non-negotiable services, and (2) deferrable and nondeferrable services. The first and second type of services are categorized into negotiable and deferrable services. Cost-oriented and environmental-oriented consumers are willing to adjust the heating and cooling temperatures to an acceptable level and shift the time to do laundry, if required, to satisfy their consumption constraints. Meanwhile, performanceoriented consumers are not willing to compromise the performance level and the time of demand fulfilment, and ultimately non-negotiable and non-deferrable service as in type-3 is provided. These design characteristics are summarized in Table 1.

While inert consumers' decisions strongly depend on the network, alternative-seeker bias can be addressed by providing low cost of information provision [33,39]. EPSS not only alters the provision but also changes the information-sharing mechanism between actors. The EPOS information-sharing mechanism modification results in two mechanisms 
for EPSS, which are characterized by information extraction from consumers for service delivery, as shown on Table 2. EPSS offering fixed price contracts are expected to address the present bias due to bounded rationality [4].

Table 1. EPSS type and description.

\begin{tabular}{ccc}
\hline EPSS Design & Design Subject & Service Design Characteristics \\
\hline EPSS type 1 & Consumer-oriented consumers & Negotiable and deferrable \\
EPSS type 2 & Environmental-oriented consumers & Negotiable and deferrable \\
EPSS type 3 & Performance-oriented consumers & Non-negotiable and non-deferrable \\
\hline
\end{tabular}

Table 2. Influential factors of consumer's decisional behavior.

\begin{tabular}{|c|c|c|}
\hline \multirow{2}{*}{ Information-Sharing Scenario } & \multicolumn{2}{|c|}{ Content of Information } \\
\hline & Information Extraction from Targeted Consumers & Information Provision from Service Provider to Consumer \\
\hline With aggregate information & $\begin{array}{c}\text { Aggregate information, collected using sample } \\
\text { survey about consumer preference in } \\
\text { service consumption }\end{array}$ & $\begin{array}{c}\text { Service rate } \\
\text { Service feature (e.g., emission generation, } \\
\text { performance level) } \\
\text { Service contract period }\end{array}$ \\
\hline With personalized information & $\begin{array}{l}\text { Personalized information can be collected using } \\
\text { individual interview about consumer preference in } \\
\text { service consumption }\end{array}$ & $\begin{array}{c}\text { Service rate } \\
\text { Service feature (e.g., emission generation, } \\
\text { performance level) } \\
\text { Service contract period }\end{array}$ \\
\hline
\end{tabular}

\subsection{Market Performance Measurements}

Regulators seek a market design that provides reliable electricity at the minimum cost for consumers through renewable energy generation. This objective is indicated by effectiveness in the short term and long term. Short-term effectiveness aims to satisfy the present demand with available resources considering consumer preferences for reliability. In this case, consumer satisfaction is the best representation of short-term performance measurement. Long-term effectiveness, on the other hand, is reflected through revenue generation to promote more investment in generation capacity to secure supply reliability in the market. The present study measures long-term effectiveness using retailer revenue considering the renewable energy mix in total consumption.

This study assumes that consumers can measure their satisfaction if information concerning their interests is available. Cost-oriented consumers measure their satisfaction based on the cost spent to satisfy their demand. Environmental-oriented consumers measure their satisfaction based on the emissions released from their consumption. While EPSS provides information on the consumer's emissions, consumers in the incumbent system have no information about it. Concerning performance-oriented consumers, their satisfaction is measured based on the performance level of the service. They prefer to choose products/services that can satisfy their demand as it is, without curtailment or postponement. When information to assess their satisfaction is not available, consumer satisfaction is recorded as zero.

Let satisfaction of cost-oriented, environmental-oriented and performance-oriented consumers, $i$, be $S_{i, c o s t}, S_{i, \text { env }}$ and $S_{i, p e r f}$, respectively; therefore, EPOS consumer satisfaction in year $-t$ is represented as

$$
S_{i, \text { ecost }}^{\mathrm{EPOS}}=\left\{\begin{array}{l}
1, \text { if } c_{i, t}<c_{i, t-1} \\
0, \text { if } c_{i, t} \geq c_{i, t-1}
\end{array} ; S_{i, \text { eno }}^{\mathrm{EPOS}}=0 ; S_{i, p e r f}^{\mathrm{EPOS}}=1\right.
$$

In EPSS, however, consumers compare their satisfaction with EPOS. The company provides information about the performance to be compared with average system performance, including EPOS and EPSS. Cost-oriented consumers in EPSS will be happy if their expenditure is lower than the average of the system. Environmental-oriented consumers are satisfied when the report of emission generation from their consumption is 
lower than the average of the system. Meanwhile, performance-oriented consumers are unhappy when their service level is different to their expectation, either in time or comfort temperature. Hence, EPSS consumer satisfaction measurement can be stated as below.

$$
S_{i, \text { cost }}^{\mathrm{EPSS}}=\left\{\begin{array}{l}
1, \text { if } c_{i, t}<\bar{c}_{t} \\
0, \text { if } c_{i, t} \geq \bar{c}_{t}
\end{array} ; S_{i, \mathrm{EPS} v}^{\mathrm{EPS}}=\left\{\begin{array}{l}
1, \text { if } e_{i, t}<\bar{e}_{t} \\
0, \text { if } e_{i, t} \geq \bar{e}_{t}
\end{array} ; S_{i, p e r f}^{\mathrm{EPSS}}=\left\{\begin{array}{l}
1, \text { if } \partial_{i, t}=\dot{\partial}_{t} \\
0, \text { if } \partial_{i, t} \neq \dot{\partial}_{t}
\end{array}\right.\right.\right.
$$

Concerning long-term efficiency, it was mentioned before that retailers in EPOS and EPSS have different sources of profit. EPOS retailers with PV generation gain revenue from renewable energy sales, both in the wholesale market and retail market. EPOS retailer revenue $\left(R_{\mathrm{EPOS}}\right)$, therefore, is formulated as follows.

$$
R_{\mathrm{EPOS}}=\sum_{t=0}^{T} \varphi_{t} \cdot\left(x_{1} \cdot P_{t}+x_{2} \cdot \hat{P}_{t}\right)+\delta_{t} \cdot\left(p+S-\hat{P}_{t}\right)
$$

It is subject to:

$$
x_{1}=\left\{\begin{array}{l}
1, \text { if } P_{t} \hat{P}_{t} \\
0, \text { if } P_{t} \hat{P}_{t}
\end{array} ; x_{2}=1-x_{1}\right.
$$

Meanwhile, EPSS revenue ( $\left.R_{\text {EPSS }}\right)$ is derived from monthly fixed service rates and sales of excess electricity. The fixed rate reflects service cost and appliance investment, including demand response and electricity storage. Hence,

$$
R_{\mathrm{EPSS}}=\sum_{t=0}^{T} \dot{\mathcal{C}} N_{\mathrm{EPSS}, t}+\left(\varphi_{t}-\delta_{t}\right) \cdot \hat{P}_{t}-\sum_{t=0}^{T} I . N_{\mathrm{EPSS}}
$$

where

$c_{i, t}$-consumer's $-i$ electricity bill at $-t-(\mathrm{JPY})$

$\overline{c_{t}}$-average consumers electricity bill at $-t$

$e_{i, t}$ - consumer's $-i$ emission at $-t-(\mathrm{CO} 2 . \mathrm{kg})$

$\bar{e}_{t}$-aggregate consumers' emission at $-\mathrm{t}-(\mathrm{CO} 2 . \mathrm{kg})$

$\partial_{i, t}$ - consumer's demand $-i$ of service performance at $-t$

$\dot{\partial}_{t}$-actual of service performance at $-t$

$\varphi_{t}$-renewable electricity generation at $-t-(\mathrm{GW})$

$\delta_{t}$-electricity sales at $-t-(\mathrm{GW})$

$x_{1}, x_{2}$-variable decision of applied electricity price rate in wholesale market

$P_{t}$-Fit-in-tariff rate at $-t-(\mathrm{JPY} / \mathrm{KWh})$

$\hat{P}_{t}$-Wholesale price rate at $-t-(\mathrm{JPY} / \mathrm{KWh})$

$p$-Electricity rate for EPOS consumer in retail market-(JPY/KWh)

$S$-Surcharge cost for renewable energy-(JPY / KWh)

$\dot{c}$-Service rate for EPSS consumer retail market-(JPY/period)

I-Investment for appliance and EPSS facility-(JPY)

$N_{\text {EPSS }}$ - Number of EPSS consumers

\subsection{Simulation and Scenario Design}

Interaction between actors in the renewable electricity market is simulated, and its impact on market performance is measured. Initially, there is $0 \%$ of renewable energy mix in total consumption before retailers which are also power PV generation companies enter the market. To stimulate investment, the regulator implements a FiT and NEM. Due to the nature of their business model, electricity generators in EPOS apply for the FiT, and Re-EPSS apply for NEM. It is assumed that the regulator is targeting $80 \%$ renewable energy penetration in 50 years, considering that many socio-technical transitions take 40-120 years [16]. Data collection includes EPSS market share, renewable energy mix, retailer revenue and aggregate consumer satisfaction. 
The present study is interested in observing the impact of decision processes of uncertain consumer bias on the performance of the renewable energy market. Re-EPSS designs are then evaluated under 36 market conditions, which are derived from selected market variables, as shown in Table 3.

Table 3. Selected variables for scenario design.

\begin{tabular}{|c|c|}
\hline Variables & Value \\
\hline Market design & (power-only market, competing market with EPSS) \\
\hline Information-sharing mechanism & (with aggregate information, with personalized information) \\
\hline Share of alternative-seeker consumers * & {$[0.15,0.25,0.35]$} \\
\hline $\begin{array}{l}\text { Share of dominant preference (i.e., as much as } 60 \% \text { of consumers } \\
\text { in the market are dominated by one of these preferences) }\end{array}$ & (cost-oriented, environmental-oriented, performance-oriented) \\
\hline
\end{tabular}

${ }^{*}$ The rest are inert consumers who are each endowed with one of status-quo bias, social influence bias and loss-averse bias. The distribution of consumers for each bias is equal.

\section{Results and Analysis}

4.1. The Impact of Heterogenous Consumer Bias and Market Competition toward Renewable Energy Market

The probability of a market with the incumbent system achieving the target of renewable energy mix is higher than that of a market with Re-EPSS introduction (i.e., $97 \%$ and $69 \%$ for incumbent and competing market, respectively). The conditions that lead to the worst results were identified to be those conditions where alternative-seeker consumers are less than $35 \%$. Fewer alternative-seeker consumers is associated with slower EPSS market penetration. It appears that in a competing market between a power-only market and EPSS (which is similar to an ancillary market), slow and low EPSS market penetration affects loss-averse investors in the power-only market. EPSS introduction amplifies the uncertainty of future revenue, due to uncertain consumer choice to remain engaged with the incumbent system or switch to the service-oriented market. The slow penetration hampers renewable energy investment for EPSS, while at the same time exposing EPOS companies to revenue risk from declining market share. As a result, both EPOS and EPSS companies suppress additional investment, which leads to even lower renewable energy mix in total consumption (see Figure 2).

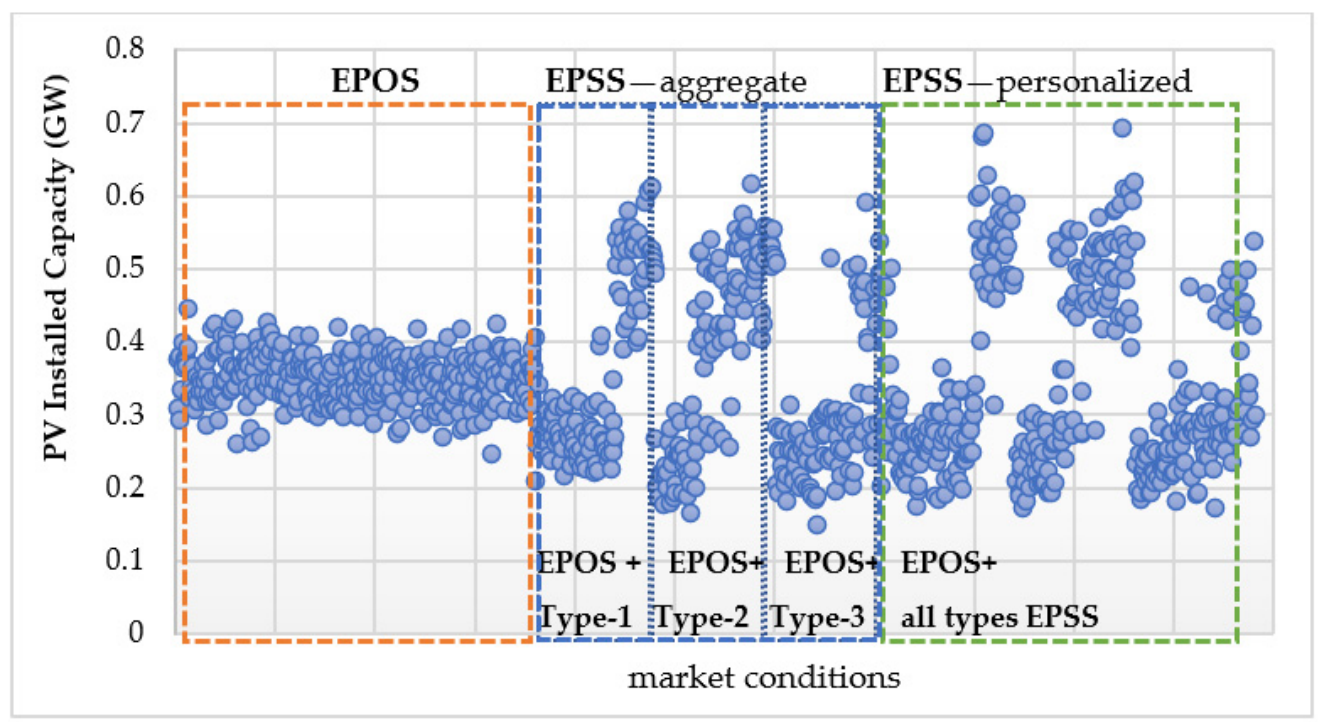

Figure 2. Market condition effect on PV installed capacity. (Data can be found in the Supplementary Materials). 
On the other hand, EPSS deploying batteries as part of their service exert an impact on increasing storage capacity in the long term. Figure 3 shows that lower storage capacity is associated with low EPSS market share. This suggests that EPSS not only stimulate investment in PV facilities but also in electricity storage. The more EPSS uptake in the market, the more reserve capacity available that will be advantageous for supply security.

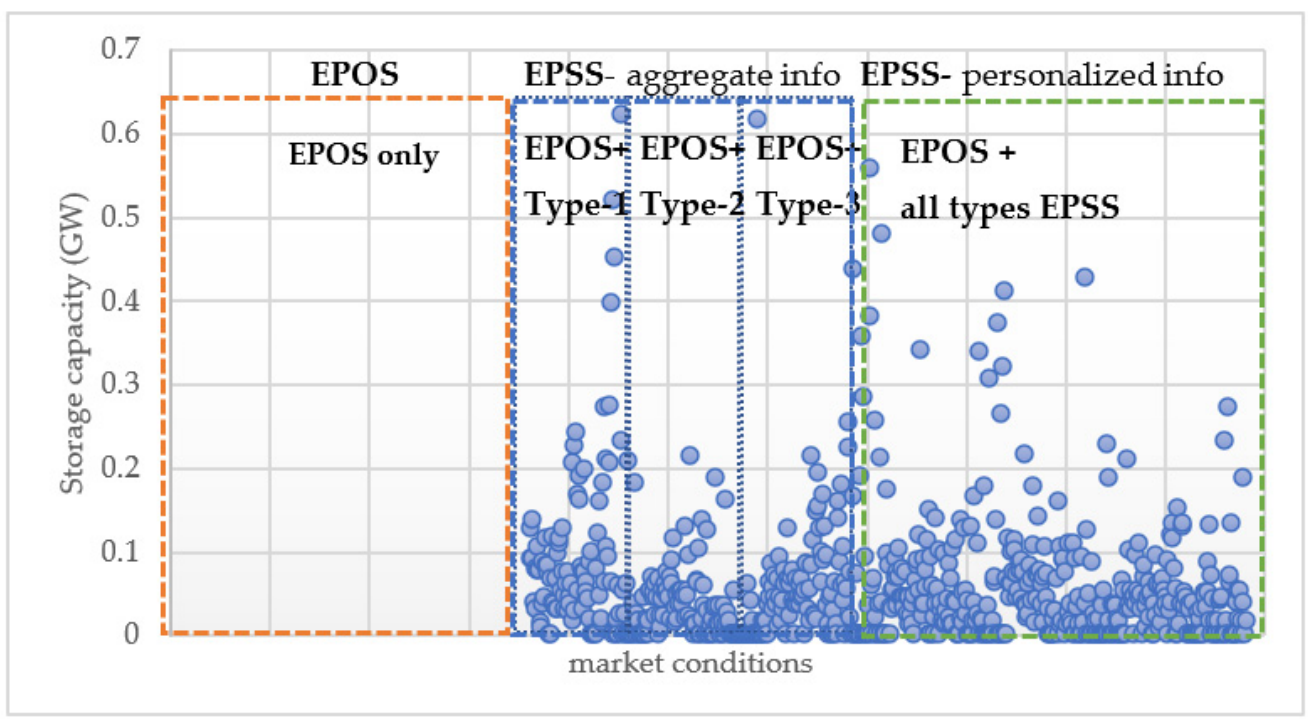

Figure 3. Market condition effect on storage capacity. (Data can be found in the Supplementary Materials).

Figure 4 shows the impact of various market conditions toward aggregate consumer satisfaction. The worst results are caused by conditions presented in Table 4 . There is a higher probability of consumer satisfaction being lower than the incumbent system where EPSS uptake in the market is relatively high. This result signifies that consumers make mistakes in their choices, similar to the incumbent system. Instead of making informed decisions considering their preferences, these consumers decide to follow social networks and market trends to avoid risk. Although consumers demonstrate similar behavior in both market mechanisms, satisfaction toward EPOS is more likely higher because consumers perceive more advantages to the incumbent [41].

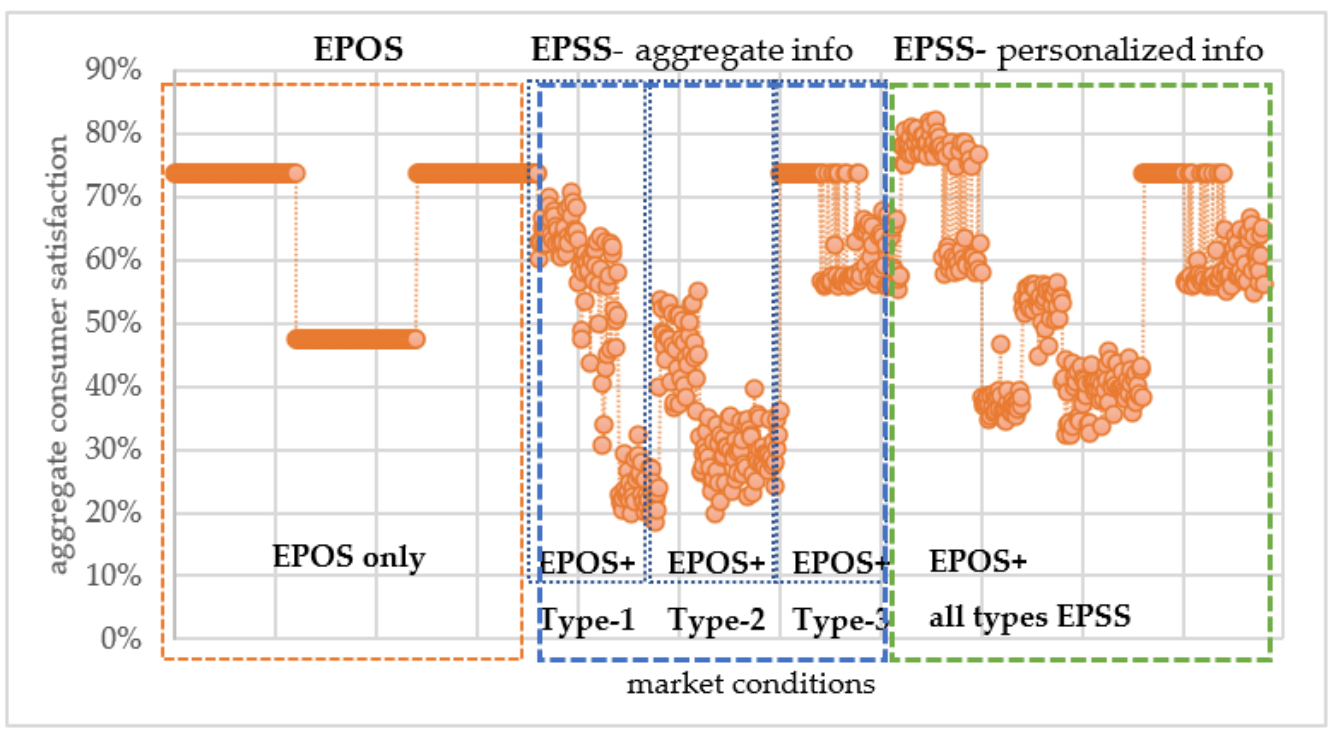

Figure 4. Market conditions' effect on aggregate consumer satisfaction. (Data can be found in the Supplementary Materials). 
Table 4. Selected variables for scenario design.

\begin{tabular}{cccc}
\hline Market Design & Information Sharing Mechanism & Share of Alternative-Seeker Consumer & Share of Dominant Preference \\
\hline Competing market & aggregate info & 0.25 & Environmental-oriented \\
Competing market & aggregate info & 0.35 & Cost-oriented \\
Competing market & aggregate info & 0.35 & Environmental-oriented \\
Competing market & personalized info & 0.25 & Environmental-oriented \\
Competing market & personalized info & 0.35 & Cost-oriented \\
Competing market & personalized info & 0.35 & Environmental-oriented \\
\hline
\end{tabular}

Analysis of Figure 5 shows that markets with EPSS generate more revenue compared to power-only markets. This result is predictable given the nature of the EPSS business model. However, the EPSS mechanism is challenged with lock-in effects from incumbent system. Other than carbon lock-in, EPSS faces barriers from society, which has been deeply rooted in product-oriented systems. With energy as the main entity, moving from product-oriented systems into service-oriented systems requires not only socio-technological transitions in the energy market system but also actors from different sectors associated with energy consumption, such as manufacturing and housing companies. Different measures are required to enable system transition from EPOS to EPSS to achieve sustainable markets for renewable energy.

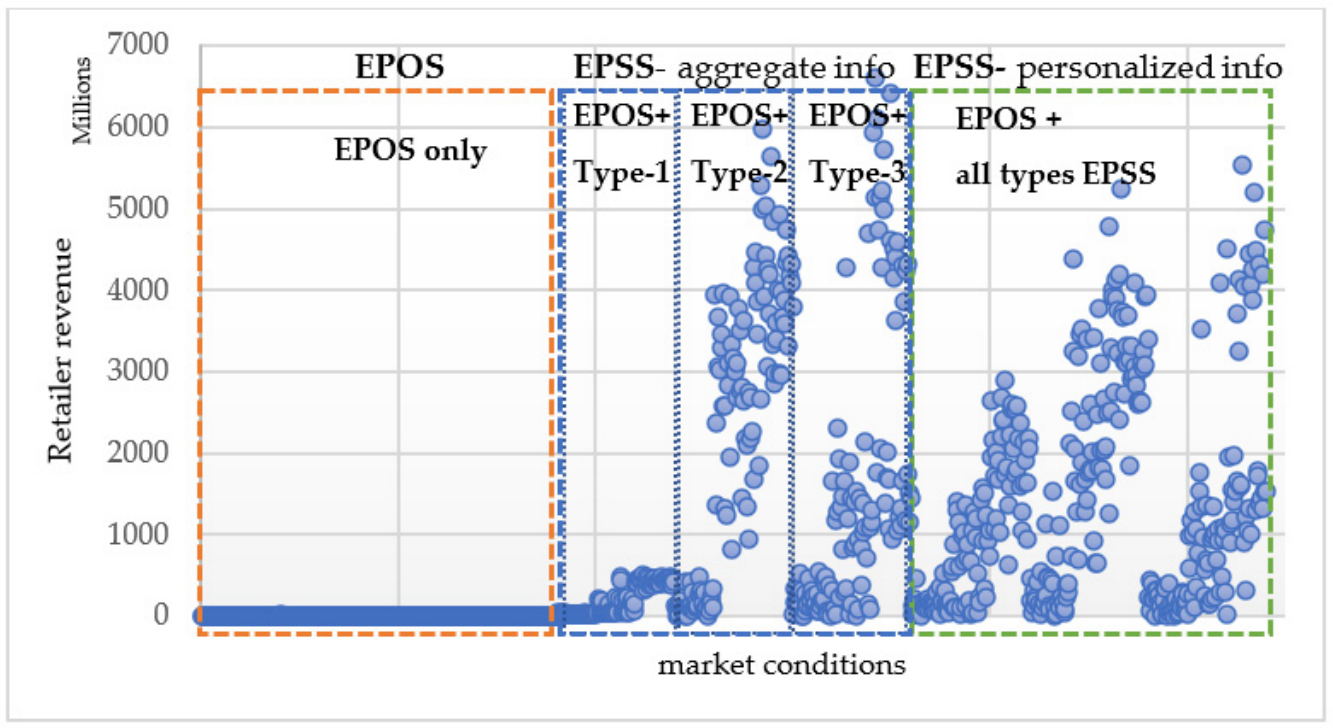

Figure 5. Market condition effect on retailer revenue. (Data can be found in the Supplementary Materials).

Accordingly, we can summarize the necessary conditions for Re-EPSS to achieve sustainable renewable energy markets as follows:

1. In terms of renewable energy investment, the result iterates the findings of previous studies that emphasize the importance of certainty for business profitability. In the case of competing market mechanisms between EPOS (as a power-only market) and EPSS (which are similar to ancillary markets), it seems better to induce measures that distinguish the market segmentation during EPSS introduction, so that initial growth of EPSS market does not amplify market uncertainty around renewable energy investment in the EPOS market.

2. Simulation results of aggregate consumer satisfaction repeat the results of the incumbent system, where consumers are satisfied with their choice. It implies that consumers' decision processes contribute to their mistakes in choosing providers. In the simulation, it was assumed that consumer consideration in the decision process is static over the time. However, in reality, there could be learning processes when feedback mechanisms to evaluate their choice are available. 
3. Retailer revenue for EPSS is predictably higher than EPOS due to its business nature. Revenue optimization from the EPSS mechanism faces barriers from product-oriented system lock-in. However, further study is necessary to investigate preconditions for EPSS in renewable electricity markets.

\subsection{Managerial Implications}

Based on the research findings, recommendations are provided to satisfy the requirements of EPSS to achieve market efficiency. Prospective benefits are important to accelerate renewable energy investment under uncertainty. It is particularly important for loss-averse business actors in power-only markets when they have to compete with EPSS business models that involve ancillary services. While EPSS transitions are challenged by path dependency of the current system, investment in power-only markets may be affected by market competition. On the other hand, investing in EPSS appears to be more profitable compared to incumbent mechanisms. For this reason, it is better to set clear boundaries to distinguish consumer segmentation for power-only markets and ancillary markets. In addition, different policy measures become indispensable for EPSS transitions. This is because the participation of different sectors associated with energy market systems is required to deliver EPSS, which means that there will be more players involved in the new energy market system.

Consumer preference for reliability is supposedly well captured in EPSS market mechanisms. However, simulation results reveal that consumers demonstrate similar failures in selecting their ideal providers, which leads to even lower satisfaction than with the incumbent system, due to an inertia effect. However, attempts to optimize consumer satisfaction can be directed towards the design of feedback mechanisms from service consumption, involving close relationships between consumers and service providers, in anticipating consumer learning processes to choose services that suit to their preferences. In this case, low switching cost is important, so that consumers can exercise their learning processes.

\section{Conclusions}

This study demonstrates the implementation of SBD to design EPSS for promoting a sustainable renewable energy market. The study used agent-based modeling with a variety of agent types. Consumers were either active or passive in their selection of alternative energy suppliers, and their preference types were either for high service quality, lowest cost or lower emissions. They would change providers depending also on the available information. Energy providers invest in renewable energy to gain revenue from FiT and satisfy their customers' demand, as well as fulfilling the regulator's renewable targets. Worst-case scenarios that lead to unexpected results have been identified. EPSS faced barriers to entry with low numbers of alternative-seeking consumers. It was highlighted that product-oriented systems could lead to higher uptake of RE in some cases.

Accordingly, it can be concluded from the study that the preconditions required for EPSS design to achieve the objective of efficient market design, both in the short term and long term, for the renewable energy market, are as follows:

1. In the case of the renewable energy market, it is necessary to set a clear boundary to distinguish consumer segmentation for power-only market and EPSS market (for ancillary service), to facilitate loss-averse investors.

2. The findings emphasize the importance of managing the close relationship between company and consumer in an attempt to extract consumer interest and create a feedback mechanism to facilitate the learning process and address consumer cognitive bias. EPSS with a better information-sharing mechanism enables the service provider to build a closer relationship with the consumers.

3. Iterating the results of previous studies, introducing a low switching cost in EPSS is indispensable for the consumer to exercise their learning process to make an informed decision in the retail market. 
Supplementary Materials: The data for figures is available as a spreadsheet online at https://www. mdpi.com/article/10.3390/en14071877/s1.

Author Contributions: This paper was primarily the work of the first author, W.K. Conceptualization, W.K., B.C.M. and T.T.; methodology, W.K.; formal analysis, W.K.; writing-original draft preparation, W.K.; writing — review and editing, B.C.M.; supervision, B.C.M. and T.T.; All authors have read and agreed to the published version of the manuscript.

Funding: This research received no external funding.

Data Availability Statement: The data for figures is supplied in the supplementary material. Other input data was from publicly available sources.

Conflicts of Interest: The authors declare no conflict of interest.

\section{Appendix A. Actors' Behavior and the Decision-Making Process}

Market players' decisions contribute to the renewable energy market's efficiency in the short term and long term. In the simulation, the decision-making process that affects market efficiency includes consumer decisions in consumption and retailer decisions in EPOS and EPSS operation, the wholesale market determines electricity price rate, and the regulator sets the feed-in-tariff rate.

\section{Appendix A.1. Consumer Behavior and the Decision-Making Process}

The flow of consumer behavior and decision-making process in both EPOS and EPSS are described in Figure A1.

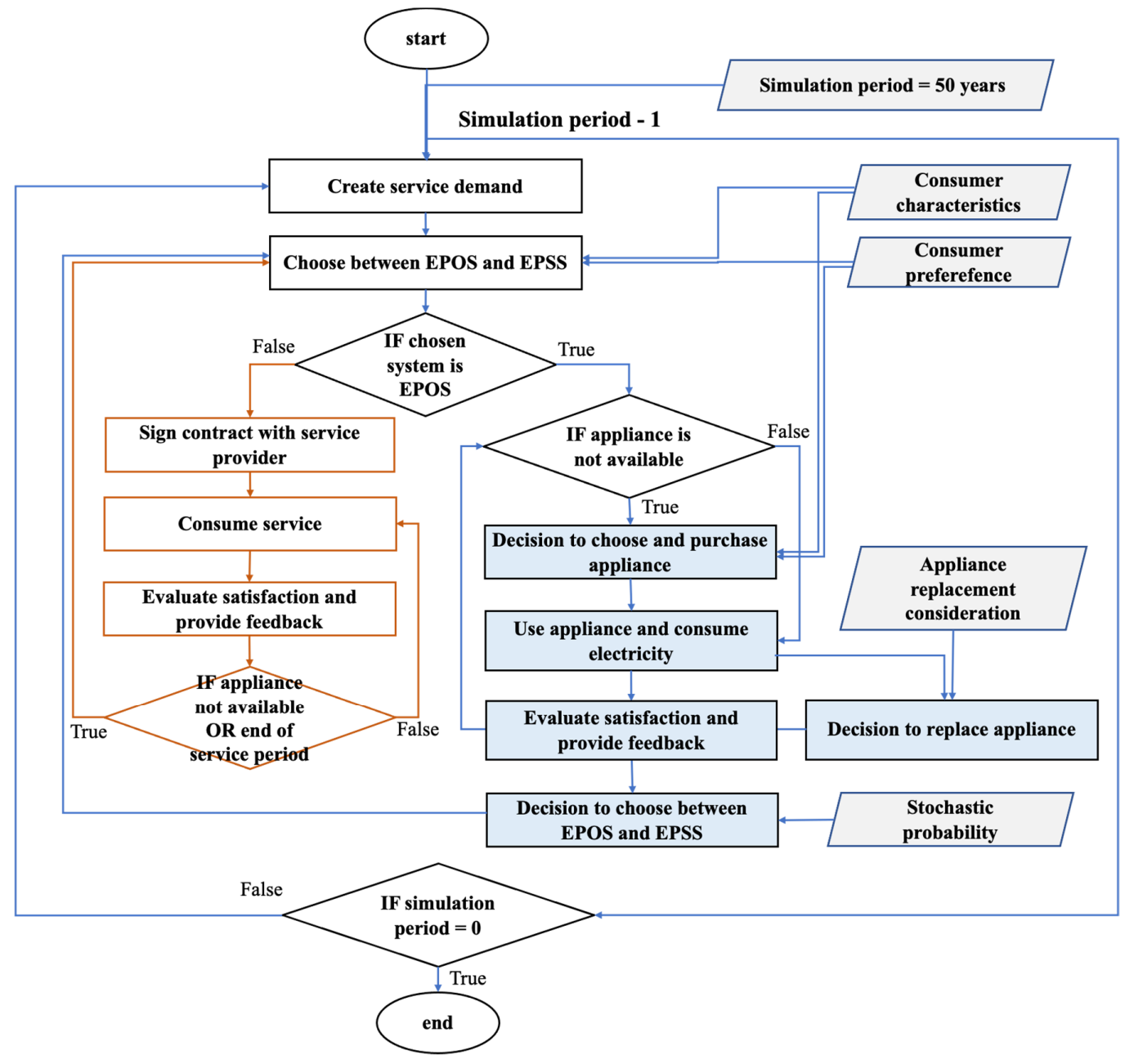

Figure A1. Consumer decision flow. 
In a market where EPSS is not available as an option, consumer demand for service leads to the demand for appliances and electricity supply. Accordingly, EPOS consumers make two decisions regarding electrical appliances, comprising (1) the decision to choose the appliance, and (2) the decision to replace and recycle the appliance. EPOS consumer choice of appliance is influenced by their characteristics and preference. The model assumes that a consumer has different preferences as considerations in choosing an appliance, including appliance prices and reviews from previous consumers. Consumers whose purchasing is constrained by willingness to pay consider purchasing appliances with the price is the closest to their budget. On the other hand, consumers that use product reviews as a consideration choose the most-used appliance in the market.

EPOS consumers replace appliances for various reasons. Ideally, consumers are expected to replace the appliance to upgrade it to the latest appliance technology. However, typical consumers tend to prolong air conditioner usage until it is broken $[61,65]$, which indicates that the appliance must be replaced. For this reason, EPOS consumers in this model use machine failure as a consideration to replace appliance. Probability of machine failure increases with the age of the appliance, especially after the appliance has been used for more than 10 years [64].

Meanwhile, in a market where the incumbent system (EPOS) competes with EPSS, alternative-seeker consumers are the first to develop the intention to choose EPSS. These consumers use the information provided to predict the benefit of adopting EPSS and compare it with their benefit experience in EPOS. EPSS provides simplified information associated with their service, including service monthly fixed rate, estimation of emission generation and service level (i.e., deferred/non deferred service supply and adjusted/nonadjusted service supply). Alternative-seeker consumers then compare the expected benefit based on their preference and choose the provision with better benefits. Cost-oriented consumers compare the cost of service delivery, environmental-oriented consumers consider the emissions generation from service consumption, and performance-oriented consumers compare the service feature that influences the service excellence. On the other hand, inert consumers will eventually consider switching to EPSS if there is information that addresses their cognitive bias. Consumers with status-quo bias choose EPSS if there is no choice other than to choose EPSS. This event occurs when companies decide to switch to EPSS for some reason. Loss/risk-averse bias consumers switch to EPSS if the market review provides evidence that the EPSS service is more satisfying than subscribing to the EPOS retailer. Consumers with social proof bias decide to switch to EPSS when most of the closest agents in their network choose EPSS.

Within the simulation period, EPSS consumers evaluate their choice when the service contract ends, i.e., when appliances are replaced, while EPOS consumers consider switching to EPSS at random periods. When they consider choosing, however, the decision is not always to switch.

For those who choose EPSS, consumers exhibit different behaviors according to the selected EPSS type. Consumers purchasing EPSS type 1 or EPSS type 2 will experience adjusted service supply, whereas at the peak electricity demand (i.e., when renewable electricity generation is equal to or less than consumers' demand for electricity service), the service supply will be deferred or adjusted to an acceptable level. Meanwhile, consumers that are subscribed to EPSS type 3 will receive the service in real time when demand occurs and without service level adjustment. EPSS consumers are not responsible for end-of-life products, because the service provider decides when to replace an appliance and decides on further processes.

Finally, consumers in both systems provide feedback to the market by reviewing their satisfaction from consumption after every period.

\section{Appendix A.2. Electricity Retailer Behavior and Decision-Making Process}

The series of processes conducted by electricity retailers in EPOS who also generate renewable energy are described in Figure A2. 


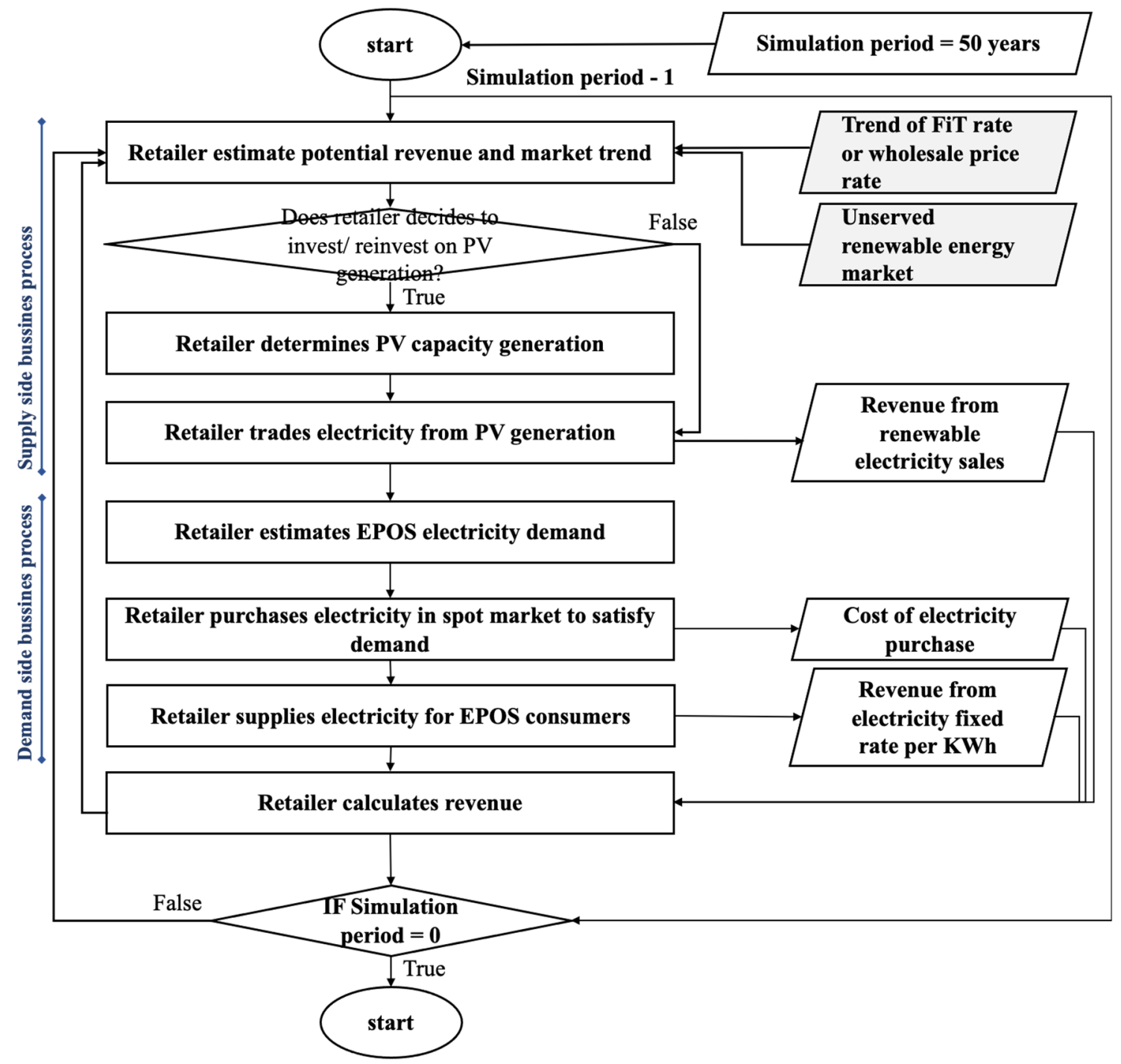

Figure A2. EPOS retailer behavior and decision flow.

EPSS generation capacity focuses on satisfying demand from EPSS consumers. The decisional flow of EPSS retailers is described in Figure A3.

In the first period, both EPOS and EPSS retailers decide to invest in PV considering the benefits from the FiT rate. For the first investment, the initial installed PV capacity is intended to satisfy the electricity demand of half of the potential consumers, which is indicated by the share of alternative-seekers. Future investment, however, is determined considering potential revenue and or renewable energy demand trend. Estimation of future revenue is the function of unserved market and current FiT rate or wholesale price rate (depending on the FiT enactment). When estimated future revenue or market trend is predicted to be promising, retailers invest more in $\mathrm{PV}$, increasing the generation capacity.

Assuming that PV specification in-use for a power generator is uniform, and the entire area receives the same amount of sunlight, electricity generation per period is a stochastic process depending on sunlight intensity during the designated time period. Electricity generated from PV is then traded in the wholesale market by the EPOS retailer, where they gain revenue from the FiT rate. On the other hand, the EPSS retailer deploys the electricity to deliver services. In EPSS, excess electricity is used to charge the storage for reserve capacity. When batteries are fully charged, and electricity generation is less than electricity demand, surplus electricity is dispatched to the main grid, and the company obtains revenue from it. In contrast, when electricity shortage occurs, reserve capacity is 
used to secure renewable electricity supply. When the reserve capacity is not sufficient to supply the service demand, if possible, the service provider adjusts the service demand to reduce the electricity demand. Nonetheless, in the event that even after service adjustment, electricity shortage is still unavoidable, the service provider purchases electricity from the spot market. The whole process of managing supply-demand balance and bridging electricity transmission from the EPSS community with the main grid is conducted by a Virtual Power Plant.

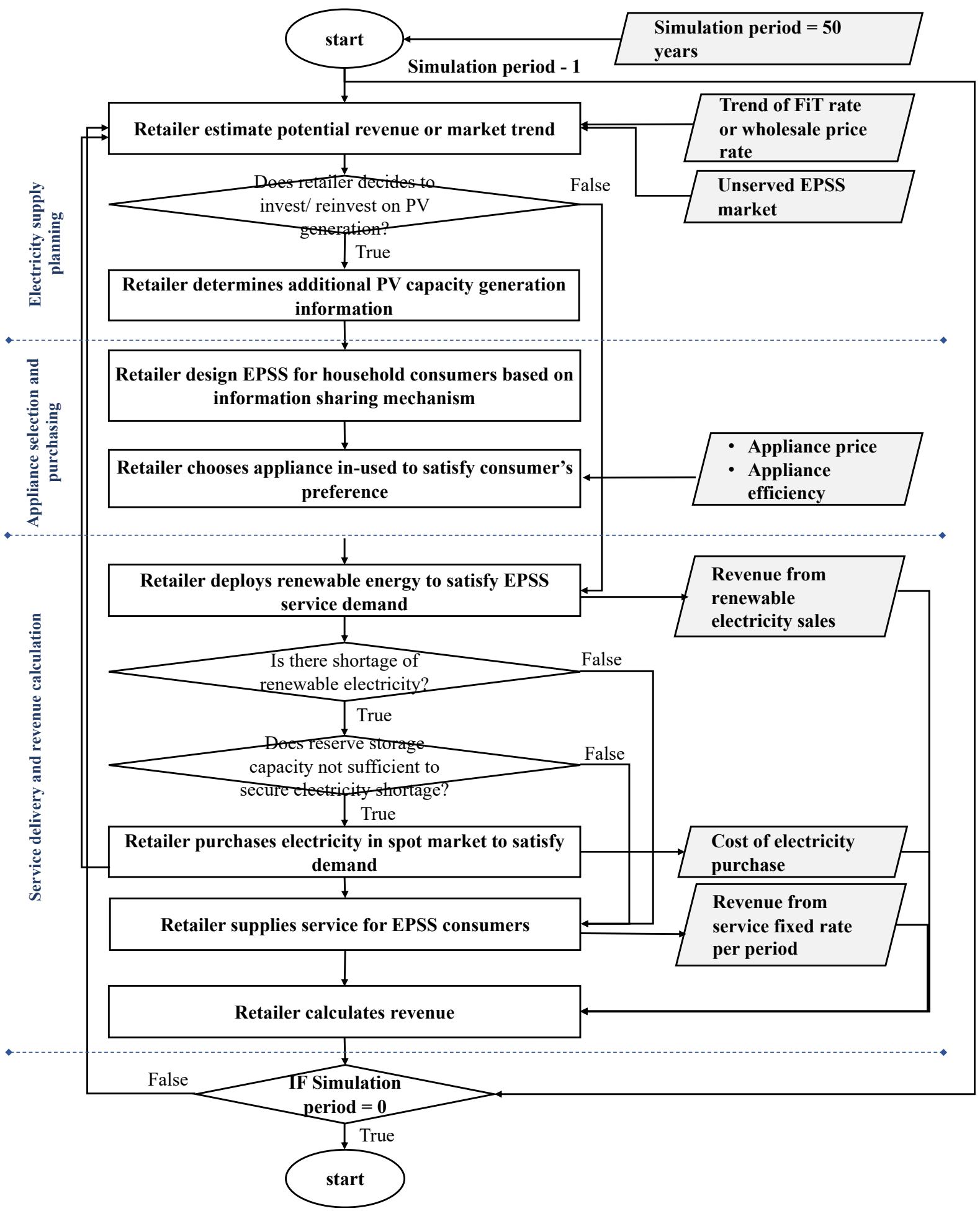

Figure A3. EPSS retailer behavior and decision flow. 
The next step is to calculate retailer revenue to send a signal to the market to elicit more renewable energy investment. EPOS retailer revenue is a function of revenue from renewable energy trading in the wholesale market, revenue from electricity sales in the retail market and cost of electricity purchased in the spot market to satisfy EPOS demand in the retail market. Meanwhile, EPSS revenue is calculated considering revenue from the fixed rate of service sales in the retail market, revenue from electricity trading in the wholesale market, minus EPSS appliance investment. While operating, companies continually evaluate market trends and potential revenue to determine future renewable energy investment. Ultimately, an EPSS retailer provides feedback to consumers by reporting their emission generation compared to the average emission generation of households in the same community.

\section{Appendix A.3. Others}

An additional mechanism in the observed market includes the FiT rate and wholesale price rate update. Feed-in-tariff is updated after every period considering the renewable energy mix of total consumption. The regulator aims for $80 \%$ renewable energy mix from total community consumption in 50 years. Initially, the FiT rate is set to $40 \mathrm{JPY} / \mathrm{KWh}$. The rate is linearly decreased when the renewable energy share of total consumption reaches $25 \%$ and $60 \%$ and ultimately revoked when renewable energy reaches $80 \%$ of total consumption. The wholesale market updates the electricity price rate every period based on the composition of electricity from renewable energy and fossil fuel trade in the market.

\section{References}

1. Chapman, A.J.; McLellan, B.; Tezuka, T. Residential solar PV policy: An analysis of impacts, successes and failures in the Australian case. Renew. Energy 2016, 86, 1265-1279. [CrossRef]

2. Agora Energiewede. 12 Insights on Germany's Energiewende 12 Insights on Germany's. 2013. Available online: https:/ /www. agora-energiewende.de/fileadmin2/Projekte/2012/12-Thesen/Agora_12_Insights_on_Germanys_Energiewende_web.pdf (accessed on 15 December 2020).

3. Kusumaningdyah, W.; McLellan, B.; Tezuka, T. Designing and Evaluating Energy Product-Service Systems for Energy Sector (EPSS) in Liberalized Energy Market: A Case Study in Space Heating Services for Japan Household. Challenges 2019, 10, 18. [CrossRef]

4. Allcott, H. Paternalism and Energy Efficiency: An Overview. Paternalism Energy Effic. Overv. 2014, 8, 145-176. [CrossRef]

5. Sovacool, B.K. Contestation, contingency, and justice in the Nordic low-carbon energy transition. Energy Policy 2017, 102, 569-582. [CrossRef]

6. Vadén, T.; Majava, A.; Toivanen, T.; Järvensivu, P.; Hakala, E.; Eronen, J. To continue to burn something? Technological, economic and political path dependencies in district heating in Helsinki, Finland. Energy Res. Soc. Sci. 2019, 58, 101270. [CrossRef]

7. Trencher, G.; Rinscheid, A.; Duygan, M.; Truong, N.; Asuka, J. Revisiting carbon lock-in in energy systems: Explaining the perpetuation of coal power in Japan. Energy Res. Soc. Sci. 2020, 69, 101770. [CrossRef]

8. Bouznit, M.; del Pablo-Romero, M.; Sánchez-Braza, A. Measures to promote renewable energy for electricity generation in Algeria. Sustainability 2020, 12, 1468. [CrossRef]

9. Lu, Y.; Khan, Z.A.; Alvarez-Alvarado, M.S.; Zhang, Y.; Huang, Z.; Imran, M. A critical review of sustainable energy policies for the promotion of renewable energy sources. Sustainability 2020, 12, 5078. [CrossRef]

10. Li, H.X.; Edwards, D.J.; Hosseini, M.R.; Costin, G.P. A review on renewable energy transition in Australia: An updated depiction. J. Clean. Prod. 2020, 242, 118475. [CrossRef]

11. Poruschi, L.; Ambrey, C.L.; Smart, J.C. Revisiting feed-in tariffs in Australia: A review. Renew. Sustain. Energy Rev. 2018, 82, 260-270. [CrossRef]

12. García-Alvarez, M.T.; Mariz-Pérez, R.M. Analysis of the Success of Feed-in Tariff for Renewable Energy Promotion Mechanism in the EU: Lessons from Germany and Spain. Procedia Soc. Behav. Sci. 2012, 65, 52-57. [CrossRef]

13. Zhang, Q.; Wang, G.; Li, Y.; Li, H.; McLellan, B.; Chen, S. Substitution effect of renewable portfolio standards and renewable energy certificate trading for feed-in tariff. Appl. Energy 2018, 227, 426-435. [CrossRef]

14. REN21. Renewables 2012 Global Status Report; REN21 Secretariat: Paris, France, 2012; pp. 1-172.

15. Dehmer, D. The German Energiewende: The First Year. Electr. J. 2013, 26, 71-78. [CrossRef]

16. Cheung, G.; Davies, P.J.; Bassen, A. In the transition of energy systems: What lessons can be learnt from the German achievement? Energy Policy 2019, 132, 633-646. [CrossRef]

17. Di Lucia, L.; Ericsson, K. Low-carbon district heating in Sweden-Examining a successful energy transition. Energy Res. Soc. Sci. 2014, 4, 10-20. [CrossRef] 
18. Poullikkas, A. A review of net metering mechanism for electricity renewable energy sources. Int. J. Energy Environ. 2013, 4, 975-1002.

19. Schelly, C.; Louie, E.P.; Pearce, J.M. Examining interconnection and net metering policy for distributed generation in the United States. Renew. Energy Focus 2017, 22-23, 10-19. [CrossRef]

20. Christoforidis, G.C.; Panapakidis, I.P.; Papadopoulos, T.A.; Papagiannis, G.K.; Koumparou, I.; Hadjipanayi, M.; Georghiou, G.E. A model for the assessment of different Net-Metering policies. Energies 2016, 9, 262. [CrossRef]

21. Hirsh, R.F.; Jones, C.F. History's contributions to energy research and policy. Energy Res. Soc. Sci. 2014, 1, 106-111. [CrossRef]

22. Goldthau, A. Rethinking the governance of energy infrastructure: Scale, decentralization and polycentrism. Energy Res. Soc. Sci. 2014, 1, 134-140. [CrossRef]

23. Geels, F.W. From sectoral systems of innovation to socio-technical systems: Insights about dynamics and change from sociology and institutional theory. Res. Policy 2004, 33, 897-920. [CrossRef]

24. Verbong, G.; Geels, F. The ongoing energy transition: Lessons from a socio-technical, multi-level analysis of the Dutch electricity system (1960-2004). Energy Policy 2007, 35, 1025-1037. [CrossRef]

25. IEA. World Energy Outlook 2020-Analysis-IEA 2020. Available online: https://www.iea.org/reports/world-energy-outlook2020 (accessed on 18 February 2021).

26. Kraan, O.; Kramer, G.J.; Nikolic, I.; Chappin, E.; Koning, V. Why fully liberalised electricity markets will fail to meet deep decarbonisation targets even with strong carbon pricing. Energy Policy 2019, 131, 99-110. [CrossRef]

27. Engelken, M.; Römer, B.; Drescher, M.; Welpe, I.M.; Picot, A. Comparing drivers, barriers, and opportunities of business models for re-newable energies: A review. Renew Sustain Energy Rev. 2016, 60, 795-809. [CrossRef]

28. Mont, O. Clarifying the concept of product-service system. J. Clean. Prod. 2002, 10, 237-245. [CrossRef]

29. Baines, T.S.; Lightfoot, H.W.; Evans, S.; Neely, A.; Greenough, R.; Peppard, J.; Roy, R.; Shehab, E.; Braganza, A.; Tiwari, A.; et al. State-of-the-art in product-service systems. Proc. Inst. Mech. Eng. Part B J. Eng. Manuf. 2007, 221, 1543-1552. [CrossRef]

30. Ost Scherer, J.; Kloeckner, A.P.; Ribeiro, J.L.D.; Pezzotta, G.; Pirola, F. Product-Service System (PSS) design: Using Design Thinking and Business Analytics to improve PSS Design. Procedia Cirp 2016, 47, 341-346. [CrossRef]

31. Van Ostaeyen, J.; Van Horenbeek, A.; Pintelon, L.; Duflou, J.R. A refined typology of product-service systems based on functional hierarchy modeling. J. Clean Prod. 2013, 51, 261-276. [CrossRef]

32. Tukker, A.; Tischner, U. New Business for Old Europe: Product-Service Development, Competitiveness and Sustainability, 1st ed.; Greenleaf Publishing Ltd.: Sheffield, UK, 2006; 479p.

33. Lindkvist, L.; Sundin, E. The role of Product-service Systems Regarding Information Feedback Transfer in the Product Life-cycle Including Remanufacturing. Procedia Cirp 2016, 47, 311-316. [CrossRef]

34. Joskow, P.L. Lessons Learned from Electricity Market Liberalization. Energy J. 2008, 29, 9-42. [CrossRef]

35. Council of European Energy Regulators (CEER). CEER Report on Commercial Barriers to Supplier Switching in EU Retail Energy Markets. 2016. Ref: C15-CEM-80-04. Available online: https://www.ceer.eu/documents/104400/-/-/bd226e4b-5542-f12c-c21e4d5a078c765d (accessed on 7 May 2018).

36. Joskow, P.L. Deregulation and Regulatory Reform in the U.S. Electric Power Sector; Center of Energy and Environmental Policy Research: Cambridge, MA, USA, 2000.

37. AEMC. 2017 AEMC Retail Energy Competition Review. Sydney, Australia. 2017. Available online: https://www.aemc.gov.au/ sites / default/files / content/006ad951-7c42-4058-9724-51fe114cabb6/2017-AEMC-Retail-Energy-Competition-Review-FINAL. pdf (accessed on 7 May 2018).

38. Morey, M.J.; Kirsch, L.D. Retail Choice in Electricity: What Have We Learned in 20 Years? 2016. Available online: https: //hepg.hks.harvard.edu/files/hepg/files/retail_choice_in_electricity_for_emrf_final.pdf (accessed on 7 May 2018).

39. Von Der Fehr, N.H.M.; Hansen, P.V. Electricity Retailing in Norway. 2008, pp. 1-41. Available online: http://idei.fr/sites/default/ files/medias/doc/conf/eem/papers_2008/vonderfehr.pdf (accessed on 9 December 2020).

40. Defeuilley, C. Retail competition in electricity markets. Energy Policy 2009, 37, 377-386. [CrossRef]

41. Hortaçsu, A.; Madanizadeh, S.A.; Puller, S.L. Power to Choose? An Analysis of Consumer Inertia in the Residential Electricity Market. Am. Econ. J. Econ. Policy 2017, 9, 192-226. [CrossRef]

42. Simon, H.A. Models of Bounded Rationality; The MIT Press: Cambridge, MS, USA, 1997; Volume 3.

43. Gigerenzer, G.; Selton, R. Bounded Rationality: The Adaptive Toolbox; Gigerenzer, G., Selton, R., Eds.; The MIT Press: Cambridge, MA, USA, 2002.

44. OECD. Using behavioural insights to increase energy conservation and energy efficiency. In Tackling Environmental Problems with the Help of Behavioural Insight; OECD Publishing: Paris, France, 2017; pp. 45-89.

45. Simon, H.A. A Behavioral Model of Rational Choice. Q. J. Econ. 1955, 69, 99-118. [CrossRef]

46. Simon, H.A. Rational choice and the structure of the environment. Psychol. Rev. 1956, 63, 129-138. [CrossRef]

47. Cramton, P. Electricity market design. Oxf. Rev. Econ. Policy 2017, 33, 589-612. [CrossRef]

48. Waechter, S.; Sütterlin, B.; Siegrist, M. Desired and Undesired Effects of Energy Labels-An Eye-Tracking Study. PLoS ONE 2015, 10, e0134132. [CrossRef]

49. Hlavá cek, I.; Chleboun, J.; Babuška, I. Uncertain Input Data Problems and the Worst Scenario Method, 1st ed.; Elsevier: Amsterdam, The Netherlands, 2004. 
50. Kraan, O.; Kramer, G.; Nikolic, I. Investment in the future electricity system-An agent-based modelling approach. Energy 2018, 151, 569-580. [CrossRef]

51. Barazza, E.; Strachan, N. The impact of heterogeneous market players with bounded-rationality on the electricity sector lowcarbon transition. Energy Policy 2020, 138. [CrossRef]

52. Kraan, O.; Dalderop, S.; Kramer, G.J.; Nikolic, I. Jumping to a better world: An agent-based exploration of criticality in low-carbon energy transitions. Energy Res. Soc. Sci. 2019, 47, 156-165. [CrossRef]

53. Kwakkel, J.H.; Yücel, G. An Exploratory Analysis of the Dutch Electricity System in Transition. J. Knowl. Econ. 2012, 5, 670-685. [CrossRef]

54. Yücel, G.; van Daalen, C. A simulation-based analysis of transition pathways for the Dutch electricity system. Energy Policy 2012, 42, 557-568. [CrossRef]

55. Mefteh, W. Simulation-Based Design: Overview about related works. Math. Comput. Simul. 2018, 152, 81-97. [CrossRef]

56. Bossak, A.M. Simulation based design. J. Mater. Process. Technol. 1998, 76, 8-11. [CrossRef]

57. Shephard, M.S.; Beall, M.W.; O’Bara, R.M.E.; Webster, B. Toward simulation-based design. Finite Elem. Anal. Des. 2004, 40, 1575-1598. [CrossRef]

58. Masad, D.; Kazil, J. Mesa: An Agent-Based Modeling Framework. In Proceedings of the 14th Python in Science Conference (SciPy 2015), Austin, TX, USA, 6-12 July 2015; pp. 51-58.

59. Wieringa, J.E.; Verhoef, P.C. Understanding Customer Switching Behavior in a Liberalizing Service Market. J. Serv. Res. 2007, 10, 174-186. [CrossRef]

60. Yang, Y. Understanding household switching behavior in the retail electricity market. Energy Policy 2014, 69, 406-414. [CrossRef]

61. Frederiks, E.R.; Stenner, K.; Hobman, E.V. Household energy use: Applying behavioural economics to understand consumer deci-sion-making and behaviour. Renew. Sustain. Energy Rev. 2015, 41, 1385-1394. [CrossRef]

62. Zeng, Y.; Zhang, J.; He, K. Effects of conformity tendencies on households' willingness to adopt energy utilization of crop straw: Evi-dence from biogas in rural China. Renew. Energy 2019, 138, 573-584. [CrossRef]

63. Du, F.; Zhang, J.; Li, H.; Yan, J.; Galloway, S.; Lo, K.L. Modelling the impact of social network on energy savings. Appl. Energy 2016, 178, 56-65. [CrossRef]

64. Fenaughty, K.; Parker, D. Evaluation of Air Conditioning Performance Degradation: Opportunities from Diagnostic Methods. 2018 ACEEE Summer Study on Energy Efficiency in Buildings. 2018. Available online: http:/ / publications.energyresearch.ucf. edu/wp-content/uploads/2018/09/FSEC-PF-474-18.pdf (accessed on 27 August 2019).

65. Bertoldi, P.; Ricci, A.; Huenges Wajer, B. (Eds.) Energy Efficiency in Household Appliances. Energy Efficiency in Household Appliances. In Proceedings of the First International Conference on Energy Efficiency in Household Appliances, Florence, Italy, 10-12 November 1997; Springer: Berlin/Heidelberg, Germany, 1999. 